\title{
Inductive Teaching and Learning in Engineering Pedagogy on the Example of Remote Labs
}

\author{
http://dx.doi.org/10.3991/ijep.v4i4.3828 \\ Raivo Sell ${ }^{1}$, Tiia Rüütmann ${ }^{1}$ and Sven Seiler ${ }^{2}$ \\ ${ }^{1}$ Tallinn University of Technology, Tallinn, Estonia \\ 2 Bochum University of Applied Sciences, Bochum, Germany
}

\begin{abstract}
Inductive principles in Engineering Pedagogy have been presented in the present paper on the example of remote labs. Inductive teaching is one way to help students learn to use the fundamental concepts for problem solving focusing on cases that students could work on to help develop an understanding of the phenomenon. For effective inductive teaching and problem solving tasks a supportive technical concept is needed. Here remotely controlled and virtual labs, which have got into focus during last years, can help a lot and offer flexibility and freedom for students. In this paper we are presenting an Engineering Pedagogy program and holistic technical solution based on remote labs for supporting the engineering studies.
\end{abstract}

Index Terms - inductive model, engineering pedagogy, robotics, remote lab, virtual lab

\section{INTRODUCTION}

The dominant teaching model in engineering is deductive, where a teacher takes full control of the transmission of knowledge - this model regards a teacher as an expert and students as a group of novices. The process of learning, thinking, and doing sends a powerful message that students receive as information about how engineers work. Numerous textbook problems, students have to solve, do not sufficiently challenge them to move to a deeper level understanding and skill of analysis that helps towards critical thinking. Learning to use concepts to analyze real-world problems is an important goal in teaching engineering, but students have very little opportunity to develop these skills today.

Inductive teaching is one way to help students learn to use the fundamental concepts for problem solving - focusing on cases that students could work on to help develop an understanding of the phenomenon before a principle is introduced. To be effective in this method hands-on experience is essential. However, today's teaching and learning process needs much more flexibility and use of different mediums. Classical lecture-exercise-exam method cannot fulfill anymore today's needs. Information and new knowledge is quite often acquired by students from Internet. This is their normal environment and to be successful of teaching engineering we need to offer also engineering subjects over the Internet, but not only as uploaded material, but interactive and real hands-on practical tasks. This is not trivial task and needs most advanced technology as well as new teaching concept in highest level. For engineering studies, online and remote labs are starting to develop in recent years. Even most of them are in experimental stage, more and more real systems can be found and used in real study process and not only for piloting. In the present article the concept of inductive principles in Engineering Pedagogy on the example of remote labs will be presented. The first part introduces concept of new engineering pedagogy and presents most recent trends and advancements. Second part of the paper presents an overview of remote lab system developed in the frame of Lifelong Learning projects and is currently in active use by several vocational schools and universities. The system supports the inductive teaching.

\section{CONCEPT OF ENGINEERING PEDAGOGY}

National systems are expressions in a very special way of a country's cultural identity. When comparing the structures of the programs of study at university level, according to International Society for Engineering Pedagogy (IGIP), the diversity could be reduced to two different university systems [1]. The so-called "Common European university approach" or Bologna Declaration has created an international standard for integrating the Engineering Pedagogy programs into European university system. Studies in Engineering Pedagogy may be independent studies after engineering studies either on Bachelor or Master level, organized in two different ways: transdisciplinary continuing education yielding a certificate (min 20 ECTS credits) or a Master's degree in Engineering Pedagogy (min 60 ECTS credits). Studies in Engineering Pedagogy may also be integrated into a long-cycle engineering program or a Master's degree program. The so-called "American system" is based on the foundation of two different consecutive programs or cycles of study Bachelor's degree (3-4 years) and Master's degree (1-2 years). Studies in Engineering Pedagogy may be integrated into either of the study cycles or follow them in minimal amount of 20 ECTS credits. In both systems it is assumed that a technical teacher has acquired a high level of technical knowledge while studying engineering and meets the requirements as defined by European Federation of National Engineering Associations (FEANI) for registration as European Engineer - EUR ING.

Estonian Centre for Engineering Pedagogy at Tallinn University of Technology has designed a new program for continuing education of technical teachers in Engineering Pedagogy, which has been registered in Estonian Ministry of Education and Research. The program in the amount of 30 ECTS credits meets the requirements of IGIP [2] and has been accredited by IGIP until 2017. The program consists of following compulsory studies: core modules (Engineering Pedagogy Science; Laboratory Didactics), theory modules (Psychology and Sociology; Ethics and 
Intercultural Competencies), practice modules (Rhetoric, Communication and Scientific Writing; Working with Projects: Curriculum Design; Media, E-Learning and Computer-Aided Technologies) and elective technology subjects (for gymnasium/K-12 technical teachers, including Robotics; Mathematics; IT and Descriptive Geometry - each in the amount of 6 ECTS credits). The amount of elective technology subjects is minimum 12 ECTS credits. The described program has become the basis of the design of a new Master's degree curriculum for technical teacher education in Estonia. Additionally there will be subjects in engineering specialty and teaching practice (min 15 ECTS credits). The studies will be completed after passing the Master's degree examination in the amount of 15 ECTS credits. To fulfill new requirement of Engineering Pedagogy program and current needs of universities a technical solution must exist. The important part of the whole technical solution is access to remote labs. Remote labs can be either distance labs where real hardware can be controller over the Internet or virtual labs where the real hardware is simulated by the computer. In both cases lab management system and supportive study material must exist to be able to use online labs in real study process. According to Müller and Erbe [3], remote labs are ideal tools also for teaching collaborative learning skills and thus later these students are more successful in collaborative engineering which is highly valued skill in today's professional engineering.

Team-based learning is one of the best examples of collaborate learning in engineering, being used in remote labs. This instructional strategy helps to create higher level understanding and may be combined with the use of the flipped classroom. In this case students reach the moderate level of understanding already in the preparation phase and afterwards they can start the application phase, solving real problems, making predictions in small group application exercises.

\section{STATE OF ART}

In March 2013 in Berlin at EDUCON2013 conference IGIP and IEEE Educational Society signed the agreement for cooperation; accordingly teachers who have passed technical teacher education based on IGIP Engineering Pedagogy curriculum will be awarded the qualification of International Engineering Educator ING-PAED IGIP. The sister organizations IGIP and IEEE-ES will start the foundation of common training centers for education of engineering educators. There are 34 training centers accredited by IGIP, e.g. in Switzerland, Germany, Austria, Netherlands, Brazil, Canada, etc [4] and 20 IGIP National Monitoring Committees all over the world, including in Estonia.

According to Felder [5], [6] instead of beginning with general principles and eventually getting applications, the instruction begins with specifics - a set of observations or experimental data to interpret, a case study to analyses, a complex real-world problem to solve or a set of activities in remote lab to implement. As the students attempt to analyze the data or scenario or solve a problem, they generate a need for facts, rules, procedures, and guiding principles, at which point they are either presented with the needed information or helped to discover it for themselves. According to Eggen \& Kauchak [7], [8] strategies are general approaches to instruction that apply in a variety of content areas and are used to meet a range of learn- ing objectives. Models are specific approaches to instruction that have four characteristics: they are designed to help students acquire deep understanding of specific forms of content and to develop their critical-thinking abilities; they include a series of specific steps that are intended to help students reach the objectives; they are grounded in learning theory, and are supported by motivation theory.

Developments and overview in remote labs are well summarized by Gomes and Garcia-Zubia [3]. There is also list of different labs available online but still most of them are in experimental stage and not methodically included into real study process. Quite often remote labs in robotics are realized by the use of National Instruments proprietary LabView software and hardware solution. For example virtual and remote robotic laboratory uses EJS, MATLAB, and LabVIEW in Spain [9], or Portuguese version of lab2go [10]. Another common approach is to use microcontroller system which can be controller over the Internet and which passes input-output signals to external devices. This approach is used in labs presented later in this paper.

\section{TEACHING RoBOTICS AND EMBEDDED SYSTEMS - METHODOLOGY}

Teaching the robotics and embedded systems in today's social environments of young people needs to apply new methodology in both, didactical and technical side. Internet is playing the crucial role for young people behavior and also as a learning environment and it cannot be discarded. On the contrary, teaching methods, including didactic approach and technical concept have to be adopted according to new requirements. According to our experience the new teaching methodology concept has been developed and named as Robotic Teaching and Learning Concept (RTLC). This concept is described in detail in the doctoral thesis $[11]$, journal papers $[12,13]$ and presented in Fig. 1.

The didactical part of the concept consists of a strategy for implementing the blended learning concept into daily education and a set of learning materials. The coherences between technical concept parts and their application in the pedagogical context based on two parts a) "Teacher/instructor" and "Student/Learner", where their point of intersection is the Network of Excellence (NoE) [14], which is the repository of teaching and learning material. Teachers tools consists of a teaching methodology, peda-

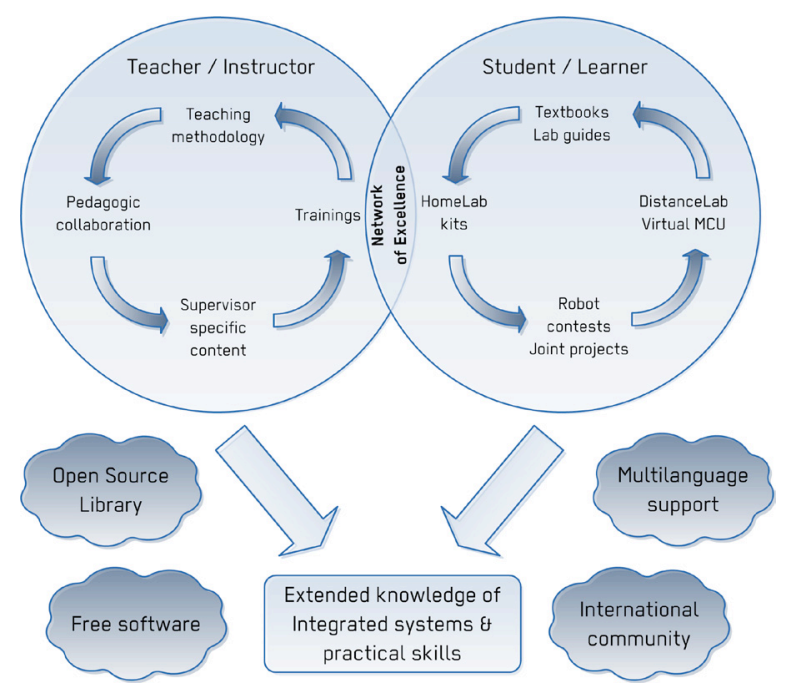

Figure 1. The Robotic Teaching and Learning Concept 
gogical collaboration with other teachers in an international platform, supervisor specific content, available through NoE and teachers training (for instance 'train the trainer' seminars), enhancing teachers knowledge of usable and available tools and content. The learners' side is supported by textbooks and lab guides and other eLearning material, which is freely accessible online through NoE. In addition, the HomeLab kit, DistanceLab and VirtualLab builds are the tools for this, leading to a robotic contest or joint student projects utilizing the introduced material. The overall goal of the concept is to extend the knowledge of integrated systems and learners practical skills.

\section{REMOTE LABS IN EMBEDDED SYSTEMS AND ROBOTICS}

Remotely controlled and virtual labs have got into focus in last years and the number of established labs is increasing rapidly. Existing online labs have very different interfaces and technical setup, starting from simple webcam enabled experiment room to complex direct manipulation and feedback evaluation systems. Some of them have been integrated into general study environment, some has just separate web interface to program the device. As the number of labs is increasing, one organization may have several different types of online labs available. In most cases there is no general lab management system yet available to manage and mediate online labs in unified way. For solving described issues the e-environment called DistanceLab portal is developed and shortly presented in this paper. DistanceLab portal is a web based system mediating and managing different type of labs. The system can handle very different type of labs and devices by offering the unified functionality. The structure of the system is presented in Fig. 2.

Currently following remote labs are most often used:

a) Robotic HomeLab kit test bench

b) Mobile robot lab

c) Manipulator lab

d) $3 \mathrm{D}$ printer $\mathrm{Lab}$

All mentioned labs belong to the embedded system domain where microcontroller is the central unit controlling the actuators and reading the inputs. These labs are used to learn and teach the microcontroller programming in $\mathrm{C}$ language with targeting to the real hardware systems found in industry.

\section{A. Robotic HomeLab test bench}

Robotic HomeLab test bench is based on Robotic HomeLab kit where the kit is assembled into small test bench system. The system consists of standard components from HomeLab basic and add-on kits. In particular, DC motor, stepper motor and servo motor as actuators and infrared, ultrasonic distance sensors, temperature sensor and photo resistor as sensors. Students can perform several exercises assigned by supervisor over the Internet by using this remote lab. The feedback of programmed controller behavior can be acquired from online videofeedback system where all test benches have their own personal camera.

\section{B. Mobile Robot Lab}

Mobile robot lab is a set of similar mobile robots driving around the arena. Robots can be booked over the Dis-

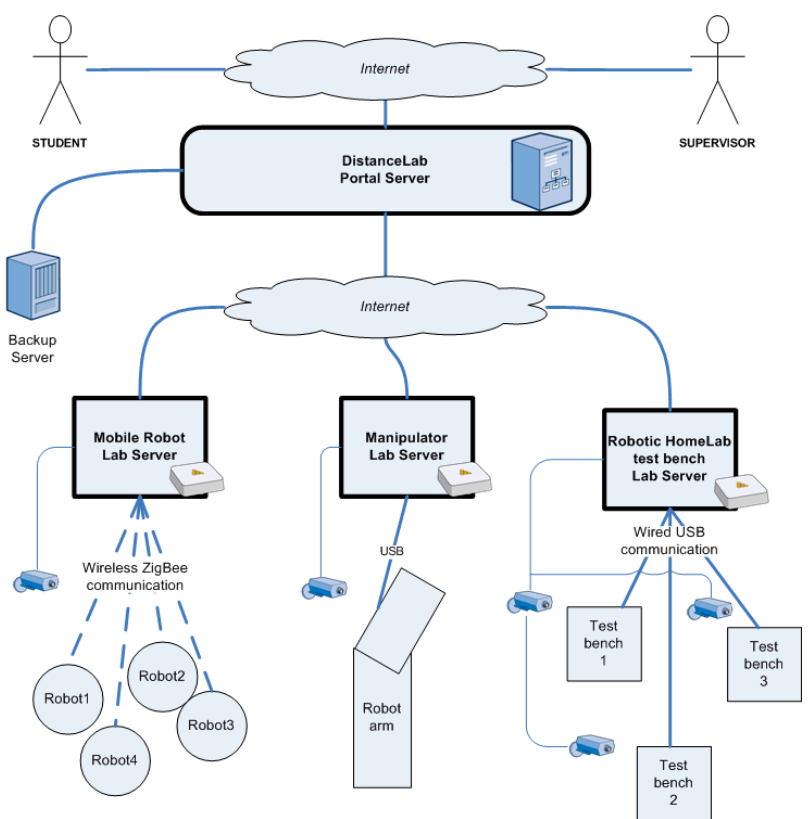

Figure 2. The structure of DistanceLab e-environment

tanceLab portal by the users with sufficient rights. Robots are based on robot platform equipped with ultrasonic distance sensor, wheel encoders and line following infrared sensors. The difference between previous lab and mobile robot lab is the camera interface. In Robotic HomeLab test bench, every device has its own personal camera whereas mobile robot lab has only two general overview cameras.

\section{Manipultor Lab}

The manipulator lab is currently consisting of three Arexx 6 DOF manipulators with small gripper. These labs are integrated into a web desktop environment, enabling students to control and program the manipulator in three different ways. First option is to directly control the six motors by a graphical user interface by moving sliders (see Fig. 3.), second one to program the arm in $\mathrm{C}$ in an online based editor. The third option to program the manipulator is a graphical programming language, where the students can choose standard blocks (like loops or other control structures with different conditions) and drag and drop them in a graphical structured representation of source code, which will be compiled to runnable binary code by a special compiler.

\section{Novelty of ApPlying ReMOte LAB IN ENGINEERING PEDAGOGY}

Schools have typically neglected teaching for thinking, and transfer thinking operations from one subject to another and to real life. Emphasis has been on information acquisition and low-level content. Students need to do more than learn information. Thinking skills and processes need to be learned, as does the ability to use these in a variety of contexts. Teaching should accomplish authentic, active, collaborative, problem-based learning is the direction proposed, along with learning to think and actively implement the acquired knowledge in labs, including remote labs.

The Inductive Model, often described as guided discovery, is a straightforward but powerful model designed to help students acquire deep and thorough understanding of 


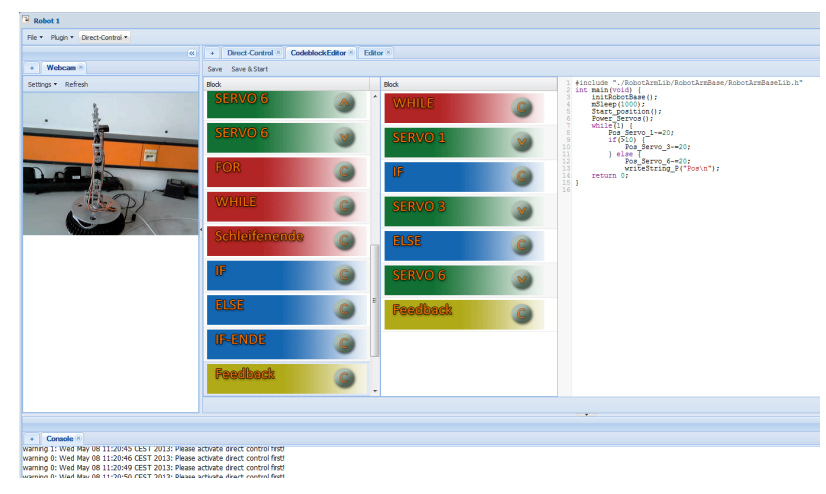

Figure 3. Fragment of Manipulator Lab user interface

well-defined topics. Grounded in the view that learners construct their own understanding, the model requires teachers to be skilled in questioning and guiding students thinking and making on-the-spot decisions. This is sophisticated and demanding instruction. The model is effective for promoting students involvement and motivation within a safe and supportive learning environment in remote labs. Introduced teaching strategies and models are designed to capacitate deep understanding and critical thinking in teaching engineering. Accordingly students will be able to explain, find evidence and examples, generalize, apply, analogies and represent a topic in a new way.

We recommend to start with realistic complex problems, let students establish what they know and what they need to find out, and then guide them inductively in finding it out by providing a combination of resources (which may include interactive mini-lectures and integrated hands-on, simulated experiments and remote labs) and guidance on performing library and Internet research.

\section{CONCLUSIONS}

Understanding is a worthwhile goal, it can reduce a chaotic mental world to a more predictable and satisfying state. It also facilitates further learning and recall of knowledge, particularly in novel situations. Understanding is often acknowledged to be an aim of learning. A teacher is not the only one who can regulate learning. Learners themselves can monitor and control their learning by developing meta-cognitive skills in remote labs.

Although few people disagree, that educating engineering students to become good learners and teachers means that they must also be good thinkers, the road towards the goal is not automatic. Helping students reach that goal takes time, knowledge, awareness and planning on the part of the teacher. Teaching students how to think is a journey, not an event.

Professional-level teaching is both an art and a science. Like an artist, a good technical teacher makes decision from both a technical and a creative perspective. Professional technical teachers develop artistry by being aware of what they are doing, and how it affects their learners. They are constantly aware that the choices they make affect the intellectual, attitudinal and psychomotor skills of their students. Above all, they make decisions.

\section{REFERENCES}

[1] IGIP Criteria for Accreditation of Engineering Pedagogy Studies, approved by IGIP Executive Committee on September 11th, 2006 www.igip.org (retrieved on April 29, 2013).

[2] IGIP Recommendations for Studies in Engineering Pedagogy Science, approved by IGIP Executive Committee on September 11the 2006 www.igip.org (retrieved on April 29, 2013).

[3] L. Gomes and J. Garcia-Zubia (eds.), Advanceson Remote Laboratories and E-learning Experiences, Deusto Publicaciones, 2006.

[4] Official web-site of IGIP www.igip.org (retrieved on April 29, 2013).

[5] R. M. Felder, "Inductive Teaching and Learning Methods: Definitions, Comparisons and Research Bases," Journal of Engineering Education. 95 (2), 2006, pp. 123-138. http://dx.doi.org/10.1002/ j.2168-9830.2006.tb00884.x

[6] R. M. Felder, "Teaching Engineering in the 21st Century with a 12th-Century Model: How Bright is that?" Chemical Engineering Education, 40(2), 2006, pp. 110-113.

[7] P. D. Egge and D. P. Kauchak, Strategies and Models for Teachers, Teaching Content and Thinking Skills, Pearson Education, 2006, 376 p.

[8] G. Borich, Effective Teaching Methods, Research-Based Practice, 7th ed., Pearson Education, 2011, 477 p.

[9] D. Chaos, J. Chacon, JA. Lopez-Orozco and S. Dormido, "Virtual and Remote Robotic Laboratory Using EJS, MATLAB and LabVIEW," Sensors Vol. 13, Issue: 2, 2013, pp. 2595-2612. http://dx.doi.org/10.3390/s130202595

[10] T. Restivo, "The Portuguese Contribution for lab2go - pt.lab2go," in International Journal of Online Engineering, vol 9, pp. 7-9, 2013.

[11] S. Seiler, supervisors R. Sell, R. Laaneots. Laboratory as a Service - A Holistic Framework for Remote and Virtual Labs. Ph.D thesis, Tallinn University of Technology Press, 2012.

[12] S. Seiler, R. Sell, D. Ptasik and M. Bölter, "Holistic web-based Virtual Micro Controller Framework for research and education," in International Journal of Online Engineering, vol 8, nr 4, 2012, pp. 58-64.

[13] R. Sell, S. Seiler, "Improvements of Multi-disciplinary Engineering Study by Exploiting Design-centric Approach, Supported by Remote and Virtual Labs," in International Journal of Engineering Education, vol. 28, issue 4, 2012, pp. 759-766.

[14] S. Seiler, R. Sell and D. Ptasik, "Embedded System and Robotic Education in a Blended Learning Environment Utilizing Remote and Virtual Labs in the Cloud, Accompanied by 'Robotic HomeLab Kit'," International Journal of Emerging Technologies in Learning, Vol 7, Issue: 4, 2012, pp. 26-33.

\section{AUTHORS}

Raivo Sell and Tiia Rüütmann are with Tallinn University of Technology, Ehitajate tee 5, 19086 Tallinn, Estonia (raivo.sell@ttu.ee, tiia.ruutmann@ttu.ee).

Sven Seiler was with Bochum University of Applied Sciences, and is now with it:matters UG, Am Erlenkamp 27 D-44801 Bochum Germany (seiler@it-matters.eu).

The development of described labs is supported by EU Life Long Learning program projects USORA and ViReal. The research is supported by ETF 8652 . It is an extended and modified version of a paper presented at the International Conference exp.at'13, held 18-20 September 2013, in Coimbra, Portugal. Submitted 30 April 2014. Published as resubmitted by the authors 05 October 2014. 